\title{
Decision Tree Based Rainfall Prediction Model with Data Driven Model using Multiple Linear Regression
}

\author{
1R.Senthil Kumar and ${ }^{2}$ Dr. C.Ramesh
}

${ }^{1}$ Research Scholar Department of Computer Science and Engineering

${ }^{2}$ Research Supervisor Satyabama University, Chennai

Correspondence Author: R.Senthil Kumar, Research Scholar, Department of Computer Science and Engineering, Satyabama University, Chennai E-mail: phdsenthilscholar@gmail.com

Received date: 23 February 2018, Accepted date: 15 June 2018, Online date: 23 June 2018

Copyright: (C) 2018 R. Senthil Kumar and Dr. C. Ramesh. This is an open-access article distributed under the terms of the Creative Commons Attribution License, which permits unrestricted use, distribution, and reproduction in any medium, provided the original author and source are credited.

\begin{abstract}
Meteorological data mining is a form of data mining concerned with finding hidden patterns inside largely available meteorological data, so that the information retrieved can be transformed into usable knowledge. Weather is one of the meteorological data that is rich in important knowledge. The most important climatic element which impacts on agricultural sector is rainfall. Thus rainfall prediction becomes an important issue in agricultural country like India. In this paper, here use data mining technique in forecasting monthly Rainfall of Tamil Nadu. This was carried out using traditional statistical technique -Multiple Linear Regression. The data include the year 2016 collected locally from Regional Meteorological Center, Chennai, Tamil Nadu, India.
\end{abstract}

Key words: Data mining, Multiple Linear Regression, Rainfall Prediction

\section{INTRODUCTION}

The decisions taken by the policy makers or research community on water resource management depend upon the predicted/forecasted scenarios generated by the models. The dependability on the end results of those models is based on accuracy at which the input parameters for the model are measured or predicted. Especially in the case of hydrological cycle is concerned, precipitation plays a vital role in initiating the entire process. The dependability on the predicted/forecasted precipitation will ensure the reliability in the estimation of the other dependable hydrological variables. To ensure the dependability on the precipitation predictions, in the recent past many models had been proposed namely time series prediction and data driven models. In the case of prediction or forecast based on previous rainfall events is concerned, the most popular and well known technique of time series forecast is multiple linear regression analysis. To utilize the knowledge of regression and moving average in a combined nature, in these statistical techniques, the present time rainfall depends upon the pervious rainfall and statistical parameters of the historical rainfall database. It conveys that statistical parameters derived from historical database govern the future rainfall events. The accuracy in statistical parameter is ensured by the length of historical database. If the database is of limited/sparse in number, then dependability on the time series forecasted rainfall pose lot of uncertainty.

On the other hand, to utilize the hidden relationship or correlation existing between rainfall events, data driven models namely artificial neural networks (ANN), genetic programming (GP), etc., are proposed by research community in recent past decade and still it is beginning an area of research. Similarly, in case of well reported data driven models such as ANN and GP, the knowledge derived from the training database ensure the accuracy in forecast. In both modelling approaches success history has be reported well with huge historical database. When

historical database is of limited nature i.e., the length of database used for arriving at statistical parameters or for training are few in number, then it may result in under or over prediction. To improve the ANN from under or over prediction of pattern, many improvements had been reported. However, the trained ANN model fails to express the mapped relationship explicitly between the input and output variables. To overcome this above drawback of data-driven models, in this research the developed methodological framework utilizes the strength and capability of recently developed data-mining algorithms to recover the knowledge from large historical database. Data mining is a process which tries to identify information or make sense of large database mostly comprising of unsupervised data [1]. This process or technique utilizes the strength/capability of statistical analysis, database systems, machine learning and pattern recognition. The capability drawn from data-driven model will mislead researchers to think both data-mining and data-driven model are one other the same. As per the definition stated by Cios et al. it can be clearly understood that the data mining process looks for the sensible patterns hidden in the large database, where as data-driven models generates patterns based on the learning process [1].

Data mining found its development and application in the recent past for analyzing market based transaction, financial transaction etc. It developed knowledge discovery process (KDP) for application in engineering field. Very few research works are reported the application of data mining particularly to water resources [2,3]. Data-mining approach has been used to derive the hidden relationships between reservoir releases and other variables. Decision tree (DT) is one of the data-mining has been used to derive the reservoir operation rules and evaluated with rules derived from linear programming optimization model and found that the DT performs better than linear programming [2,3]. Further, the efficiency of DT algorithm is evaluated by comparing with the optimal rules derived from regression based rules for flood control reservoir (Wei and Hsu, 2008), and inferred that DT based reservoir rule curves performed better than the regression based rules.

The rules derived from DT algorithm are easier to understand from explicit expression between the attributes and the decision-making variable. Data mining has been widely used in the area of reservoir operation for extracting the hidden relationship that exists in the historical database and utilizing the same for predicting the future reservoir operation rules. In this research work an attempt has been made to incorporate the strength of DT data-mining algorithm to recover 
the relationship that exists between climatic variables and the rainfall historical database. The developed framework utilizes the recovered knowledge for predicting the future rainfall events. ANN is a complex data driven model to represent non-linear input/output relationship. ANN can be applied in various fields, viz. approximation, pattern recognition and classification, optimization and prediction [4]. ANN is based on training, not on statistical or analytical assumption. ANN model can be trained to predict results from information at very high speed [5]. The friction factor of the external flow over pile of circular tubes is estimated by using both multiple linear regression and ANN approaches. The better results were observed in ANN [6]. Azimian has also applied ANN to predict the friction factor for the flow inside a pipe [7]. The back propagation method, a gradient-descent algorithm that minimizes the error between the output of the training input/output pairs and the actual network outputs, is used to adjust the connecting weights [8]. It has justified that ANN predicts highly complex relationships between the input and the output variables. The research on rainfall modeling proposed. Prediction of daily inflow of reservoir.

\subsection{Seasonal rainfall forecast for Southwest monsoon, 2016 for different districts of Tamil Nadu:}

Tamil Nadu is a rain shadow area to South West Monsoon (SWM), nearly 32 percent of the total annual rainfall of Tamilnadu is received from this monsoon. Farmers of Dharmapuri, Krishnagiri, Salem, The Nilgris and Kanyakumari are benefitted from this seasonal rainfall to take up strategic farm decisions. District level rainfall forecast for the ensuing Southwest monsoon, 2016 (June to September) over Tamil Nadu was developed at Agro Climate Research Centre, Tamil Nadu Agricultural University, Coimbatore based on the Southern Oscillation Index of summer season and Sea Surface Temperature values of Pacific and Indian Oceans using Australian Rainman International V.4.3.Software. The historical rainfall data collected from Tamil Nadu Agricultural University Stations were used to represent the district rainfall information. In the absence of data from research station in a particular district, data from Rainman software were used. Normal Rainfall ( $\pm 19 \%$ from mean seasonal rainfall) is expected in Ariyalur, Chennai, Cuddalore, Dindigul, Dharmapuri, Erode, Karur, Kancheepuram, Kanyakumari, Krishnagiri, Madurai, Namakkal, Perambalur, Pudukottai, Salem, Sivagangai, Thanjavur, Theni, Tirunelveli, Tutucorin, Trichy, The Nilgiris, Tiruppur, Tiruvallur, Tiruvannamalai, Villupurum, Vellore, Virudhunagar. Deficit Rainfall (> -19\% to -59\% from mean seasonal rainfall) is expected in Coimbatore, Nagapattinam, Ramanathapuram and Tiruvarurdistricts. Rainfall expected during Southwest monsoon, 2016 with 60 per cent probability is given below

\begin{tabular}{|c|c|c|c|c|c|c|c|}
\hline $\begin{array}{l}\text { S. } \\
\text { No }\end{array}$ & Districts & $\begin{array}{l}\text { Long } \\
\text { Period } \\
\text { Average } \\
\text { Rainfall } \\
(\mathrm{mm})\end{array}$ & $\begin{array}{l}\text { Rainmane } \\
\text { xpected } \\
\text { rainfall(m } \\
\mathrm{m})\end{array}$ & $\begin{array}{l}\text { Deviation } \\
(\%)\end{array}$ & Category & $\begin{array}{l}\text { AgriculturalI } \\
\text { mportance }\end{array}$ & $\begin{array}{l}\text { Water } \\
\text { Conservation }\end{array}$ \\
\hline 1 & The Nilgiris & 759.9 & 691 & -9 & Normal & $\sqrt{1}$ & \\
\hline 2 & Kanyakumari & 477.4 & 455 & -5 & Normal & $\sqrt{ }$ & \\
\hline 3 & Vellore & 466.1 & 438 & -6 & Normal & $\sqrt{ }$ & \\
\hline 4 & Chennai & 439.1 & 428 & -2 & Normal & - & $\sqrt{ }$ \\
\hline 5 & Kancheepuram & 490.8 & 420 & -14 & Normal & $\sqrt{ }$ & \\
\hline 6 & Salem & 440.6 & 420 & -5 & Normal & $\sqrt{ }$ & \\
\hline 7 & Tiruvallur & 451.6 & 418 & -7 & Normal & $\sqrt{ }$ & \\
\hline 8 & Tiruvannamalai & 468.1 & 412 & -12 & Normal & $\sqrt{ }$ & \\
\hline 9 & Krishnagiri & 399.0 & 391 & -2 & Normal & $\sqrt{ }$ & \\
\hline 10 & Dharmapuri & 393.4 & 369 & -6 & Normal & $\sqrt{ }$ & \\
\hline 11 & Pudukottai & 350.6 & 365 & 4 & Normal & $\sqrt{ }$ & \\
\hline 12 & Cuddalore & 383.1 & 358 & -7 & Normal & $\sqrt{ }$ & \\
\hline 13 & Ariyalur & 392.0 & 356 & -9 & Normal & $\sqrt{ }$ & \\
\hline 14 & Villupurum & 408.3 & 335 & -18 & Normal & $\sqrt{ }$ & \\
\hline 15 & Namakkal & 339.3 & 310 & -9 & Normal & $\sqrt{ }$ & \\
\hline 16 & Perambalur & 290.7 & 308 & 6 & Normal & $\sqrt{ }$ & \\
\hline 17 & Sivagangai & 301.0 & 305 & 1 & Normal & $\sqrt{ }$ & \\
\hline 18 & Trichy & 293.9 & 305 & 4 & Normal & $\sqrt{ }$ & \\
\hline 19 & Maduari & 335.9 & 276 & -18 & Normal & & $\sqrt{ }$ \\
\hline 20 & Thanjavur & 318.4 & 269 & -15 & Normal & & $\sqrt{ }$ \\
\hline 21 & Dindugal & 295.4 & 246 & -17 & Normal & & $\sqrt{ }$ \\
\hline 22 & Nagapattinam & 286.1 & 227 & -21 & Deficit & & $\sqrt{ }$ \\
\hline 23 & Tiruvaur & 296.4 & 226 & -24 & Deficit & & $\sqrt{ }$ \\
\hline 24 & Virdhunagar & 196.8 & 205 & 4 & Normal & & $\sqrt{ }$ \\
\hline 25 & Erode & 229.8 & 195 & -15 & Normal & & $\sqrt{ }$ \\
\hline 26 & Karur & 213.6 & 185 & -13 & Normal & & $\sqrt{ }$ \\
\hline 27 & Coimbatore & 189.8 & 152 & -20 & Deficit & & $\sqrt{ }$ \\
\hline 28 & Tiruppur & 154.8 & 148 & -4 & Normal & & $\sqrt{ }$ \\
\hline 29 & Theni & 158.4 & 147 & -7 & Normal & & $\sqrt{ }$ \\
\hline 30 & Ramanathapuram & 149.3 & 118 & -21 & Deficit & & $\sqrt{ }$ \\
\hline 31 & Tirunelveli & 142.4 & 116 & -19 & Normal & & $\sqrt{ }$ \\
\hline 32 & Tuticorin & 74.9 & 77 & 3 & Normal & & $\sqrt{ }$ \\
\hline
\end{tabular}




\begin{tabular}{|c|c|c|c|c|c|c|c|}
\hline & GOVERNM & ENT OF INI & DIA, MINIST & RY OF & TH SCIEN & CES & \\
\hline & & DIA METEC & OROLOGIC & L DEF & VENT & & \\
\hline & REGIO & AL METE & OROLOGICA & AL CEN & CHENN & & \\
\hline & Districtwise daily / season & | rainfall dist & ribution for $\mathrm{Ta}$ & mil Nad & ducherry of & date 10.03.201 & \\
\hline PREI & IONSOON 2017 RAINFAL & & $0.03 .2017^{\text {ktk }}$ & & From 01 & 03.2017 to 10 . & 2017 \\
\hline CODE & NAME & $\begin{array}{c}\text { ACTUAL in } \\
\mathrm{mm}\end{array}$ & NORMAL in mm & PDN $^{*}$ & $\begin{array}{c}\text { ACTUAL in } \\
\mathrm{mm}\end{array}$ & NORMAL in $\mathrm{mm}$ & $\mathrm{PDN}^{*}$ \\
\hline & STATES & & & & & & \\
\hline 32 & PUDUCHERRY (UT) & 0.0 & 3.0 & -100 & 70.4 & 13.0 & 444 \\
\hline 31 & TAMIL NADU & 2.8 & 0.5 & 517 & 15.8 & 6.4 & 147 \\
\hline & & & & & & & \\
\hline & MET. SUBDIVISIONS & & & & & & \\
\hline 31 & TAMIL NADU \& PUDUCHERRY & & & & & & \\
\hline 534 & ARIYALUR & 0.0 & 0.6 & -100 & 2.5 & 5.1 & -50 \\
\hline 461 & CHENNAI & 0.0 & 0.6 & -100 & 0.0 & 0.9 & -100 \\
\hline 462 & COIMBATORE & 11.8 & 0.3 & 3833 & 42.9 & 6.3 & 582 \\
\hline 463 & CUDDALORE & 0.0 & 0.5 & -100 & 3.6 & 6.3 & -43 \\
\hline 464 & DHARMAPURI & 0.0 & 0.4 & -100 & 11.7 & 5.2 & 124 \\
\hline 465 & DINDIGUL & 1.2 & 0.4 & 200 & 19.7 & 7.4 & 167 \\
\hline 466 & ERODE & 8.0 & 0.4 & 1906 & 22.4 & 4.6 & 387 \\
\hline 467 & KANCHEEPURAM & 0.0 & 0.4 & -100 & 0.0 & 1.0 & -100 \\
\hline 468 & KANYAKUMARI & 0.4 & 0.8 & -50 & 14.6 & 8.7 & 68 \\
\hline 636 & KARAIKAL & 0.0 & 0.2 & -100 & 185.5 & 7.2 & 2476 \\
\hline 469 & KARUR & 24.8 & 0.0 & 200 & 39.5 & 4.0 & 888 \\
\hline 470 & KRISHNAGIRI & 0.0 & 0.3 & -100 & 35.2 & 4.0 & 780 \\
\hline 471 & MADURAI & 4.3 & 0.2 & 2030 & 51.1 & 6.7 & 662 \\
\hline 472 & NAGAPATTINAM & 0.0 & 0.8 & -100 & 46.8 & 8.3 & 464 \\
\hline 473 & NAMAKKAL & 5.6 & 0.1 & 5471 & 8.0 & 3.4 & 136 \\
\hline 474 & NILGIRIS & 3.0 & 2.6 & 15 & 17.0 & 16.0 & 6 \\
\hline 475 & PERAMBALUR & 0.0 & 0.3 & -100 & 6.5 & 4.6 & 41 \\
\hline 476 & PUDUCHERRY & 0.0 & 4.6 & -100 & 7.6 & 16.1 & -53 \\
\hline 477 & PUDUKOTTAI & 1.6 & 0.1 & 1467 & 10.3 & 5.4 & 90 \\
\hline 478 & RAMANATHAPURAM & 0.0 & 0.4 & -100 & 26.4 & 8.7 & 203 \\
\hline 479 & SALEM & 5.0 & 0.2 & 2419 & 9.2 & 4.9 & 88 \\
\hline 480 & SIVAGANGA & 0.0 & 0.1 & -100 & 13.6 & 6.4 & 112 \\
\hline 481 & THANJAVUR & 2.3 & 0.4 & 472 & 15.8 & 8.7 & 82 \\
\hline 482 & THENI & 3.1 & 1.0 & 206 & 29.2 & 12.4 & 136 \\
\hline 483 & TIRUNELVELI & 2.0 & 1.2 & 67 & 20.3 & 15.6 & 30 \\
\hline 535 & TIRUPPUR & 11.6 & 0.1 & 11500 & 15.0 & 4.2 & 258 \\
\hline 484 & TIRUVALLUR & 0.0 & 0.5 & -100 & 1.4 & 1.4 & -2 \\
\hline 485 & TIRUVANNAMALAI & 0.0 & 0.1 & -100 & 0.0 & 4.6 & -100 \\
\hline 486 & TIRUVARUR & 0.0 & 0.9 & -100 & 8.9 & 6.9 & 29 \\
\hline 488 & TOOTHUKUDI & 0.4 & 1.4 & -70 & 5.6 & 11.6 & -52 \\
\hline 487 & TIRUCHIRAPALLI & 3.1 & 0.2 & 1433 & 19.5 & 4.9 & 298 \\
\hline 489 & VELLORE & 0.0 & 0.1 & -100 & 1.2 & 2.8 & -57 \\
\hline 490 & VILLUPURAM & 0.0 & 0.3 & -100 & 3.8 & 3.8 & 1 \\
\hline 491 & VIRUDHUNAGAR & 0.0 & 0.5 & -100 & 10.3 & 10.2 & 1 \\
\hline & SUBDIVISION RAINFALL & 2.8 & 0.5 & 503 & 16.0 & 6.4 & 149 \\
\hline LEGEND & PDN $^{*}$ & & & Percentag & ture from Norn & & \\
\hline & ** & & Rainfall & for the 24 & ling at $0830 \mathrm{~h}$ & 3 of date & \\
\hline
\end{tabular}

\section{Literature Review:}

Kannan, prabhakaran and ramachandran [2] computed Pearson coefficient for five years data and then compared with predicted data using regression approach. Here, the prediction of rainfall is by using multiple linear regression method. The predicted values lie below computed values. According to the results, it does not show accuracy but show an approximate value.

Andrew, Xiupeng, Anoop and Evan [3] applied five data mining algorithms to predict rainfall in watershed basin at oxford, Iowa, based on radar reflectivity and tipping bucket (TB) data. The five algorithms are employed to build rainfall prediction model such as neural network, random forest, classification and regression tree, support vector machine and k-nearest neighbor. Three Models are selected for all future time horizons. Three models are, Model I is the baseline model constructed from radar data covering oxford. Model II predicts rainfall from radar and TB data collected at south Amana (16 km west oxford) and Iowa City ( $25 \mathrm{~km}$ east of oxford). Among 5 algorithms MLP neural network has the best performance in comparison to other algorithms. According to the computational results, they have indicated that the three models had a similar performance in predicting rainfall at current time, and model II was more than the other models in predicting rainfall at future time horizons. Different lags like $t+15, t+30, t+45, t+60, t+75, t+90, t+105, t+120$ were considered. The longest acceptable prediction horizon is $120 \mathrm{~min}$. 
Jesada, Kok and Chung [4] proposed fuzzy inference system for monthly rainfall prediction in the northeast region of Thailand. The predicted performance of the proposed model was compared to be conventional Box-Jenkins and artificial neural networks model. Accordingly, the experimental results show the modular FIS is good alternative method to predict accurately. The predicted mechanism can be interpreted through fuzzy rules. Auto-regression, Seasonal auto regressive integrated moving average and ANN modular FIS provide better results. The experimental results provide both accurate results and humanunderstandable prediction mechanism.

Mark, Bobby, Yung and Beth proposed time series analysis is used as prediction algorithm. Two components rainfall/evaporation and crop management. Decision support system for Agriculture management using prediction algorithm aimed to develop a system that will determine the trend of rainfall and evaporation using time series analysis as its prediction algorithm, to develop web-based application that displays graphs and tables according to the result of the prediction algorithm, and to utilize a classification of crops that aids farmers as basis for recommendation according to the predicted amount of rainfall per quarter. The system is found useful in terms of efficiency, reliability. It shows interface the quarter of the year labeled Q1, Q2,Q3, Q4, prediction of average amount of rainfall and evaporation, the trends, and the seasonal effects in its provided field in the table.

Kyaw and Othman [5] proposed Focused time delay neural network for rainfall forecasting. The network is trained by using Levenberg-Marquardt to perform one-step-ahead predictions. Here, the dataset of rainfall is converted into monthly, quarterly, biannually, yearly. Among these dataset, the yearly dataset gave most accurate results (94.25\%) with testing data. The accuracy decreases for the biannual, quarterly and monthly datasets $(81.11 \%, 76.03 \%, 56.02 \%)$. In FTDNN dynamics appear only a input layer of a static multilayer feed-forward network, which makes it suitable for time series prediction.

Ramesan, Shamin and Mathew [6] proposed Neural Network Auto Regressive with exogenous input (NNARX) and adaptive neuro-fuzzy inference system for rainfall runoff phenomenon effectively from antecedent rainfall and runoff information. The models which are having various input structures were constructed and the best structure was investigated with help of the proposed technique, called Gamma test. Prior to model, training data length selection and best input combination is carried out with help of Gamma test. According to the paper, the ANFIS and NNARX work efficiently in rainfall - runoff model and provide high accuracy and reliability in runoff prediction.

\section{Proposed Architecture:}

The overall architecture of the system is shown in Figure 1. The NCEP/NCAR datasets are preprocessed using prestd function. It is fed as inputs for training. The rainfall values are clustered using subtractive clustering and the rainfall states identified as low, medium, heavy and given as outputs for training. Separating data into training and testing sets is an important part of evaluating data mining models. When we separate a data set into a training set and testing set, most of the data is used for training, and a smaller portion of the data is used for testing. Here $80 \%$ of the dataset is used for training and the remaining $20 \%$ for testing.

\section{Data Collection and Preprocessing:}

Datasets for rainfall prediction downloaded from official website of National Oceanic and Atmospheric Administration (NOAA) maintained by US Department of Commerce. The NOAA is a scientific agency within the United States Department of Commerce focused on the conditions of the oceans and the atmosphere. NOAA warns of dangerous weather, charts seas and skies, guides the use and protection of ocean and coastal resources, and conducts research to improve understanding and stewardship of the environment.

NOAA maintains NCEP/NCAR Reanalysis data. The NCEP/NCAR Reanalysis data set is a continually updating gridded data set representing the state of the Earth's atmosphere, incorporating observations and numerical weather prediction (NWP) model output dating back to 1948. It is a joint product from the National Centers for Environmental Prediction (NCEP) and the National Center for Atmospheric Research (NCAR). The National Centers for Environmental Prediction (NCEP) and National Center for Atmospheric Research (NCAR) have cooperated in a project called reanalysis to produce a retroactive record of more than 50 years of global analyses of atmospheric fields in support of the needs of the research and climate monitoring communities. These data were then quality controlled and assimilated with a data assimilation system kept unchanged over the reanalysis period. This eliminated perceived climate jumps associated with changes in the operational (real time) data assimilation system, although the reanalysis is still affected by changes in the observing systems.

The National Centers for Environmental Prediction (NCEP) and the National Center for Atmospheric Research (NCAR) have accomplished different reanalysis projects which aim on the generation of global data sets for a long time period for different atmospheric parameters. The re-analysis is created with a model similar to the one used for weather forecasts. This model is initialized with measured data from different sources, including observations from weather stations, ship, aircraft, and satellite. Using one model for the whole re-analysis period generates homogeneous data that can be used for long term studies. NCEP/NCAR has produced several re-analyses that are described on their web-page. This free data set is updated continuously and has therefore many users worldwide.

\subsection{Feature Extraction:}

It is the technique of selecting a subset of relevant features for building robust learning models. Many features like Temperature, Evaporation, Wind Speed, Terrain features, Height from sea level, humidity, Precipitable water affects the rainfall .Out of it, the most relevant five features are considered in this paper. The following are the features selected.

\subsubsection{Relative Humidity:}

Relative humidity is a term used to describe the amount of water vapor in a mixture of air and water vapor. It is defined as the ratio of the partial pressure of water vapor in the air-water mixture to the saturated vapor pressure of water at the prescribed temperature. The relative humidity of air depends not only on temperature but also on the pressure of the system of interest. Relative humidity is often used instead of absolute humidity in situations where the rate of water evaporation is important, as it takes into account the variation in saturated vapor pressure.

\subsubsection{Pressure:}

Air pressure varies over time and from place to place and these temporal differences are usually caused by the temperature of the air. Cool air is denser (heavier) than warm air. Warm air is less dense (lighter) than cool air and will therefore rise above it. Areas of high pressure can be caused when cool air is sinking and pressing on the ground. At this time, the weather is usually dry and clear. In contrast, when warm air rises, it causes a region of low pressure. With low pressure, the weather is often wet and cloudy.

\subsubsection{Temperature:}

Atmospheric temperature is a measure of temperature at different levels of the Earth's atmosphere. It is governed by many factors, including incoming solar radiation, humidity and altitude. Air temperature is the intensity aspect of sun's energy that strikes the earth's surface. Because the amount of energy from the sun reaching the earth varies from day to day, from season to season, and from latitude to latitude, temperatures also vary. The earth as a whole receives a constant flow of radiant short-wave energy from the sun. The earth also radiates long-wave energy to space. During the day, the flow of short-wave radiation absorbed exceeds long -wave energy emitted, and the surface temperature increases.

\subsubsection{Precipitable Water:}

Precipitable water is the depth of water in a column of the atmosphere if all the water in that column were precipitated as rain. The total atmospheric water vapor contained in a vertical column of unit cross-sectional area extending between any two specified levels, commonly expressed in terms of the height to which that water substance would stand if completely condensed and collected in a vessel of the same unit cross section.

\subsubsection{Wind Speed:}

Wind is the flow of gases on a large scale. On Earth, wind consists of the bulk movement of air. Wind is caused by differences in pressure. When a difference in pressure exists, the air is accelerated from higher to lower pressure. Wind speed is affected by a number of factors and situations, operating on 
varying scales. These include the pressure gradient, Rossby waves and jet streams, and local weather conditions. There are also links to be found between wind speed and wind direction, notably with the pressure gradient and surfaces over which the air is found.

\subsection{Data Processing:}

Downloaded datasets are in NetCDF (nc) format. NetCDF (Network Common Data Form) is a set of software libraries and self-describing, machineindependent data formats that support the creation, access, and sharing of array-oriented scientific data. Two packages are used to convert NC Format to ASCII. They are NetCDF\& FAN. Unidata's NetCDF package includes ncdump, which is used to display the metadata from a NetCDF file. ncdump -h filename will display only the header information, without any of the actual data. Data is stored in the NetCDF files in 2D arrays. To extract the data, we need to know the name of the variable and the array indices of the grid cell we want to extract. Give ghtext the filename, the variable, and the indices redirecting the output to a text file Harvey Davies' FAN (File Array Notation) is an array-oriented language for identifying data items in files for the purpose of extraction or modification. In this paper, the utility ghtext which is available in FAN is used to convert netCDF data to plain text.

Data preprocessing steps were applied on the new set of seasonal data and they were converted to nominal values by applying filters using unsupervised attribute of discretization algorithm. After the operations were carried, a total of 1254 instances were present for analysis. The discretization algorithm produced various best fit ranges [Table 1] for the five atmospheric conditions which we used in analysis.

Table 1: Nominal Values for Atmospheric Parameters

\begin{tabular}{|c|c|c|}
\hline \multirow{3}{*}{ Temperature } & $T_{L}$ & $<81$ \\
\hline & $\mathrm{T}_{\mathrm{M}}$ & $76-81$ \\
\hline & $\mathrm{T}_{\mathrm{H}}$ & $>84$ \\
\hline \multirow{3}{*}{ Dew Point } & $\mathrm{D}_{\mathrm{L}}$ & $<68$ \\
\hline & $\mathrm{D}_{\mathrm{M}}$ & $68-71$ \\
\hline & $\mathrm{D}_{\mathrm{H}}$ & $>71$ \\
\hline \multirow{3}{*}{ Wind Speed in Knots } & $\mathrm{W}_{\mathrm{L}}$ & $<5.4$ \\
\hline & $\mathrm{W}_{\mathrm{M}}$ & $5.5-10.5$ \\
\hline & $\mathrm{W}_{\mathrm{H}}$ & $>10.00$ \\
\hline \multirow{3}{*}{ Visibility in Miles } & $\mathrm{V}_{\mathrm{L}}$ & $<4$ \\
\hline & $V_{M}$ & $5-7$ \\
\hline & $\mathrm{V}_{\mathrm{H}}$ & $>6.5$ \\
\hline \multirow{2}{*}{ Precipitation } & Yes & $>0$ \\
\hline & No & $=0$ \\
\hline
\end{tabular}

The C5 [9] is the latest version of the ID3 and C4.5 algorithms developed by Quinlan in the last two decades. The criterion employed in See5 algorithm to carry out the partitions is based on the concepts from Information Theory and has been improved over time. The main idea is to choose the variable that provides more information to realize the appropriate partition in each branch in other to classify the training set. One advantage of Decision Tree classifiers is that rule can be inferred from the trees generated that are very descriptive, helping users to understand their data.See5 software can generate both decision trees and decision tree rules depending on selected options. The Trees and rules were generated using 10 fold cross validation and the results with the least error on the test data set were selected. Table 3 presents the summary of the runs and the decision tree obtained from Run Number 6 which had the least error.

Table 3: Summary of decision tree results

\begin{tabular}{|c|c|l|}
\hline Run No & $\begin{array}{l}\text { No of Trees } \\
\text { Generated }\end{array}$ & Error \\
\hline 1 & 21 & $58.3 \%$ \\
\hline 2 & 19 & $50.0 \%$ \\
\hline 3 & 21 & $41.7 \%$ \\
\hline 4 & 18 & $41.7 \%$ \\
\hline 5 & 16 & $753.0 \%$ \\
\hline 6 & 17 & $33.3 \%$ \\
\hline 7 & 15 & $58.3 \%$ \\
\hline 8 & 21 & $41.7 \%$ \\
\hline 9 & 18 & $58.3 \%$ \\
\hline 10 & 17 & $50.0 \%$ \\
\hline Mean & 18.3 & $50.8 \%$ \\
\hline SE & 0.7 & $3.8 \%$ \\
\hline
\end{tabular}

See5 decision tree generated:

MaxTemp<= 32.2:

$\therefore .$. MaxTemp $<=29.6$ :

$:$ :...Wind <= 129.93: $\operatorname{sep}(7)$

$\therefore$ : Wind $>129.93$ :

$\therefore:$ :...Radiation $<=9.6$ : aug $(11 / 2)$

$:$ : Radiation > 9.6: jul (6)

: MaxTemp> 29.6:

$:$ :...Wind <= 118.26: oct $(9 / 1)$

: Wind > 118.26:

: :...MaxTemp> 31: may $(9 / 1)$

: MaxTemp<=31:

$\therefore: .$. MinTemp $<=22.2: \operatorname{sep}(2)$

: MinTemp> 22.2: Jun (10/2)

MaxTemp> 32.2:

$\therefore$. MaxTemp $<=34$ : 
:...Rainfall> 81.6: april (10/2)

: Rainfall $<=81.6$ :

: :...MinTemp<= 23.3:

$:$ :...Wind $<=101.2: \operatorname{dec}(3 / 1)$

$:$ : Wind >101.2: jan (11/2)

: MinTemp> 23.3:

: :...MaxTemp<= 33.2: nov (5)

: MaxTemp> 33.2: dec (4/1)

MaxTemp> 34:

:...Wind < = 117.65: dec (2)

Wind > 117.65:

....MinTemp<= 23.7: feb $(6 / 1)$

MinTemp> 23.7:

....MaxTemp<= 34.2: feb $(2 / 1)$

MaxTemp> 34.2:

...MinTemp<= 24.8:mar(9/1)

MinTemp> 24.8: feb (2)

The See 5 decision tree results can also be presented in the form of rules (See5 rules) which are easier to understand and use. Each rule consists of

1. A rule number that serves only to identify the rule

2. Statistics ( $\mathrm{n}$, lift $\mathrm{x})$ or $(\mathrm{n} / \mathrm{m}$, lift $\mathrm{x})$ that summarize the performance of the rule

$3 . \mathrm{n}$ is the number of training cases covered by the rule and $\mathrm{m}$ shows how many of them do not belong to the class predicted by the rule. The rule's accuracy is estimated by the Laplace ratio $(n-m+1) /(n+2)$. The lift $x$ is the result of dividing the rule's estimated accuracy by the relative frequency of the predicted class in the training set

4. One or more conditions that must all be satisfied for the rule to be applicable

5. Class predicted by the rule

6. A value between 0 and 1 that indicates the confidence with which this prediction is made, and

7. Default class that is used when none of the rules apply.

The summary of the runs for the generation of See 5 rules on the test data set using 10 fold cross validation is presented in Table 4 and twelve of the rules from Run Number 7 which had the least errors are presented:

Table 4: Summary of results of See5 rules generation process

Table 4: Summary of results of See5 rules generation

\begin{tabular}{|l|c|c|}
\multicolumn{3}{|c}{ process } \\
\hline $\begin{array}{l}\text { Run } \\
\text { No }\end{array}$ & $\begin{array}{r}\text { No of } \\
\text { Rules } \\
\text { Generated }\end{array}$ & Error \\
\hline 1 & 13 & $58.3 \%$ \\
\hline 2 & 16 & $50.0 \%$ \\
\hline 3 & 14 & $41.7 \%$ \\
\hline 4 & 16 & $50.0 \%$ \\
\hline 5 & 16 & $33.3 \%$ \\
\hline 6 & 13 & $58.3 \%$ \\
\hline 7 & 16 & $25.0 \%$ \\
\hline 8 & 17 & $33.3 \%$ \\
\hline 9 & 15 & $33.3 \%$ \\
\hline 10 & 20 & $41.7 \%$ \\
\hline Mean & 15.6 & $42.5 \%$ \\
\hline SE & 0.7 & $3.6 \%$ \\
\hline
\end{tabular}

See5 rules generated

Rule 1: (57/48, lift 2.0)

MaxTemp> 32

->classjan [0.169]

Rule 2: (6/1, lift 9.0)

Wind $>150.66$

MinTemp $>24.4$

MaxTemp> 34

->classfeb [0.750]

Rule 3: (3, lift 9.6)

Wind $>131.45$

Wind $<=150.66$

MinTemp $>23.7$

MaxTemp> 34

->class mar [0.800]

Rule 4: (8/1, lift 9.6)

Wind $>141.98$

MaxTemp $>32$

MaxTemp $<=34$

Rainfall > 33.1

->classapril [0.800]

Rule 5: (2, lift 9.0)

Wind $>131.45$

Wind $<=141.98$ 
MaxTemp> 32

Rainfall > 33.1

->class may [0.750]

Rule 6: (10/2, lift 9.0)

Wind $>118.26$

MinTemp> 22.2

MaxTemp $>29.6$

MaxTemp $<=31$

->classjun [0.750]

Rule 7: (6, lift 10.5)

Wind $>129.93$

Radiation $>9.6$

MaxTemp $<=29.6$

->classjul [0.875]

Rule 8: (11/2, lift 9.2)

Radiation $<=9.6$

MaxTemp $<=29.6$

->classaug [0.769]

Rule 9: (2, lift 9.0)

Wind $>118.26$

MinTemp $<=22.2$

MaxTemp $>29.6$

MaxTemp $<=32$

->classsep [0.750]

Rule 10: $(8$, lift 10.8)

Wind $<=118.26$

MaxTemp> 29.6

MaxTemp $<=32$

$\rightarrow$ classoct [0.900]

Rule 11: (9/2, lift 8.7)

Wind $<=131.45$

MaxTemp $>32$

MaxTemp $<=33.1$

->classnov [0.727]

Rule 12: (12/3, lift 8.6)

Wind $<=131.45$

MaxTemp > 33.1

Rainfall <= 18.7

->classdec [0.714]

Here in this work the C5 decision tree classification algorithm was used to generate decision trees and rules for classifying weather parameters such as maximum temperature, minimum temperature, rainfall, evaporation and wind speed in terms of the year 2016.

\section{CONCLUSIONS:}

In this work the $\mathrm{C} 5$ decision tree classification algorithm was used to generate decision trees and rules for classifying weather parameters such as maximum temperature, minimum temperature, rainfall, evaporation and wind speed in terms of the year 2016. Artificial Neural Networks can detect the relationships between the input variables and generate outputs based on the observed patterns inherent in the data without any need for programming or developing complex equations to model these relationships. Hence given enough data ANN's can detect the relationships between weather parameter and use these to predict future weather conditions. Both TLFN neural networks and Recurrent network architectures were used to developed predictive ANN models for the prediction of future values of Wind speed, Evaporation, Radiation, Minimum Temperature, Maximum Temperature and Rainfall given the Month and Year.

\section{REFERENCES}

[1] Sivaramakrishnan, T.R., 1989. “Annual Rainfall over Tamil Nadu”, Hydrology Journal,IAH, p: 20.

[2] Sivaramakrishnan, T.R., et al., 1983,“A study of rainfall over Madras - Vayumandal, p: 69.

[3] Sivararamakrishnan, T.R and S. Sridharan, 1987. "Occurrence of heavy rain episodes over Madras, Proceedings of National symposium on Hydrology, NIH, Roorkee, P VI 54.

[4] Sivaramakrishnan, T.R., S. Meganathan and P. Sibi, "An analysis of northeast monsoon rainfall for the Cauvery delta of Tamil Nadu", Proceedings

[5] Negm, A.M., A.A. Ibrahim, A.A. El-Saiad, A.M. Al-Brahim, 2004. Flow resistance due to cylindrical piles. Egyptian Journal of Engineering Science and Technology, 7: 123-234.

[6] Azimian, A.R., 2005. Application of artificial neural networks in pipe flow calculations. 4th International Conference on Heat Transfer, Fluid Mechanics and Thermodynamics. Egypt. pp: 19-22.

[7] Agrawal, R., T. Imielinski, A. Swami, 1993. Mining Association Rules between Sets of Items in Large Database. ACM SIGMOD Conference on Management of Data. Washington.

[8] Chang, L.C., F.J. Chang, 2001. Intelligent control for modelling or real-time reservoir operation. Hydrological Processes, 15: 1621-1634.

[9] Chaves, P., T. Tsukatani, T. Kojiri, 2004. Operation of storage reservoir for water quality by using optimization and artificial intelligence techniques. Mathematics and Computers in Simulation, 67: 419-432.

[10] Dawson, C.W., R. Wilby, 1998. An artificial neural network approach to rainfall runoff modelling. Hydrological Sciences Journal, 43: 47-66. 